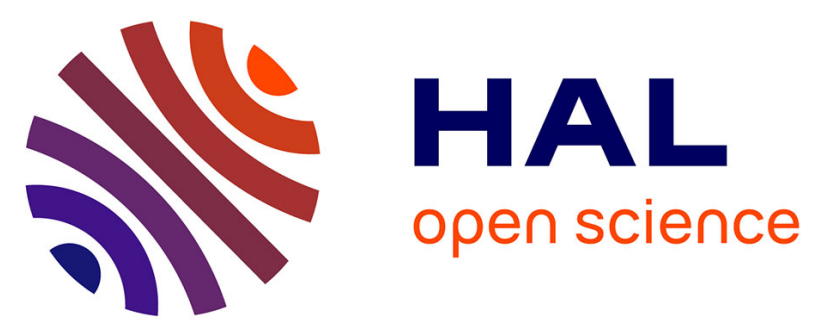

\title{
Hybrid Material Based on the Lindquist Polyoxometalate [W6O19]2- and the organosulfur donor o-Me2TTF: A Combined Structural and Spectroscopic Study
}

Eric W. Reinheimer, Damian Jankowski, Roman Swietlik, Marc Fourmigué

\section{To cite this version:}

Eric W. Reinheimer, Damian Jankowski, Roman Swietlik, Marc Fourmigué. Hybrid Material Based on the Lindquist Polyoxometalate [W6O19]2- and the organosulfur donor o-Me2TTF: A Combined Structural and Spectroscopic Study. Journal of Chemical Crystallography, 2013, 43 (4), pp.178-186. 10.1007/s10870-013-0403-4 . hal-00931808

\section{HAL Id: hal-00931808 https://hal.science/hal-00931808}

Submitted on 28 Jan 2014

HAL is a multi-disciplinary open access archive for the deposit and dissemination of scientific research documents, whether they are published or not. The documents may come from teaching and research institutions in France or abroad, or from public or private research centers.
L'archive ouverte pluridisciplinaire HAL, est destinée au dépôt et à la diffusion de documents scientifiques de niveau recherche, publiés ou non, émanant des établissements d'enseignement et de recherche français ou étrangers, des laboratoires publics ou privés. 
J Chem Crystallogr (2013) 43:178-186

DOI $10.1007 /$ s10870-013-0403-4

ORIGINAL PAPER

Hybrid Material Based on the Lindquist Polyoxometalate

[W6019] 22

and the organosulfur donor o-Me2TTF: A Combined

Structural and spectroscopic study

Eric W. Reinheimer •

Damian Jankowski

Roman S wietlik •

Marc Fourmigue'

Received: 15 July 2012 / Accepted: 25 February 2013 / Published online: 30 March 2013

Springer Science+Business Media New York 2013

Abstract The synthesis, crystal structure and spectroscopic properties of the hybrid radical cation salt containing oxidized o-3,4-dimethyltetrathiafulvalene (o-Me2TTF) and the Lindquist polyoxometalate anion [W6019]2-are reported. The title salt represents the first time a Lindquist polyoxometalate has been utilized as the counter anion with this unsymmetrical member of the TTF family of derivatives. The salt crystallizes in the triclinic space group $\mathrm{P}$ 1with $\mathrm{a}=7.6211(7) \mathrm{A}^{\circ}$ $\mathrm{b}=9.5231(9) \mathrm{A}^{\circ}, \mathrm{C}=12.2148(11) \mathrm{A}^{\circ}, \mathrm{a}=105.5870(10)$, $\mathrm{b}=106.8340(10)$. and $\mathrm{c}=95.6950(10)$. Resolution of the solid state structure revealed that the o-Me2TTF radical cations aggregate as isolated face-to-face dimers with intradimer interactions between neighboring sulfur atoms at distances $\backslash 3.6 \mathrm{~A}^{\circ}$. Hydrogen bonding was also observed between hydrogen atoms bound to sp 2-hybridized carbon atoms of o-Me2TTF and bridging oxygen atoms of [W6019]2-. Single crystal IR and Raman spectra were also collected and provide further evidence that the o-Me2TTF donors have been oxidized to their corresponding radical cationic states.

E. W. Reinheimer.

M. Fourmigue'

Institut des Sciences Chimiques de Rennes, UMR 6226

CNRS-Universite' Rennes 1, Campus de Beaulieu,

35042 Rennes, France

Institute of Molecular Physics, Polish Academy of Sciences, ul. M. Smoluchowskiego 17, 60-179 Poznan', Poland

D. Jankowski.

R. S wietlik

Present Address:

E. W. Reinheimer (\&)

Department of Chemistry and Biochemistry and W.M. Keck 
Foundation Center for Molecular Structure, California State

University San Marcos, 333 S. Twin Oaks Valley Road,

San Marcos, CA 92096, USA

e-mail: ereinhei@csusm.edu

Keywords Electrocrystallization .

TTF .

o-Me2TTF .

Polyoxometalate

\section{Introduction}

A focus of contemporary Materials Science is the preparation of molecule based materials that display active physical properties such as conductivity, ferromagnetism or non-linear optical properties [1]. With the initial discovery of metallic conductivity in TTF-TCNQ as well as the first and second generation of organic superconductors, materials containing oxidized organosulfur (or organoselenium) donors were identified as those most likely to display elevated conductivity (or superconductivity) [2-4]. Most advantageous to the observation of either non-activated conductivity or superconductivity within these materials was the solid state aggregation of the oxidized donors into long range stacks which created a more facile pathway for the transfer of itinerant electron density.

As the study into electroactive materials persisted, interest in materials that displayed multifunctionality began to manifest. Through the directed, rational synthesis of solid networks in the form of salts, where each ionic network furnished a distinct physical property to the material, the multifunctional materials known as magnetic conductors were prepared [5]. The molecular ferromagnet, (BEDT-TTF) $3[\operatorname{MnCr}(\mathrm{C} 204) 3]$. $\mathrm{CH} 2 \mathrm{Cl} 2$ (BEDT-TTF = bis (ethylenedithio) tetrathiafulvalene or ET) served as a 'proof of concept'" because conducting layers of partially oxidized ET donors were successfully combined with paramagnetic layers of oxalato-bridged bimetallic complexes to form a material which displayed both metallic conductivity ( $\mathrm{RTT}=250 \mathrm{~S} \mathrm{~cm}-1)$ and ferromagnetically coupled metal atoms $(\mathrm{TC}=5.5 \mathrm{~K})$ [6].

Oxalato-bridged bimetallic anions are not the only class of inorganic anions studied in the preparation of hybrid 
salts containing derivatives of TTF. In an effort to further study how novel lattice architectures and physical properties resulting from the association of organic radical cations can be affected by large anions, the use of large polyoxometalate clusters as anions in hybrid salts has been probed. Due to their elevated solubility in organic solvents, ability to possess variable charges and shapes which may alter the corresponding band structure and possibility of incorporating paramagnetic metal atoms into the polyoxoanion core, this class of anions is an ideal candidate for incorporation into hybrid and multifunctional materials [7].

With the Lindquist clusters, with the formula (M6019)2( $\mathrm{M}=$ Mo or $\mathrm{W}), 2: 1$ phases involving TTF, TMTTF

(tetramethyltetrathiafulvalene), ET, BET-TTF (bis (ethylenethio) tetrathiafulvalene), TPTTF (tetraphenyltetrathiafulvalene) and DMDPTTF (dimethyldiphenyltetrathiafulvalene) have been reported [8-13]. Later a 2:1 phase involving [W6019]2and the donor bis (propylene)dithiotetrathiafulvalene (BPDTTTF) was communicated [14]. In all cases, those salts were found to contain isolated dimers of radical cations and were insulating. Meanwhile, $3: 1$ and $4: 1$ phases containing TTF and TMTSF were discovered and found to be semiconducting [15, 16]. Finally, a 5:1 hybrid salt involving ET and the substituted Lindquist anion [VW5019]3-which displayed metallic conductivity, was reported by Ouahab and coworkers in 1993

[17]. While the Lindquist polyoxometalates have yielded a large number of results, other polyoxoanion clusters have also yielded salts when combined with TTF derivatives such as ET. When ET was combined with the polyoxovanadate cluster [H3V10028]3-and the Dawson-Wells anion [P2W18062]6-, the salts (ET) 5[H3V10028] 4H2O and (ET) 11[P2W18062]. 3 H2O resulted and were found to possess metallic conductivity $[18,19]$. Finally, Keggin polyoxometalate clusters with

FeIII

the generic formulae [XZM11039]5-(XZM11 = SiIVCrIII

Mo11, SiIVW11, PVCoIIW11, PVNiIIW11, PVCuIIW11, PVZnIIW11, PVMnIIW11 and PVMnIIMo11) were combined with ET to make the salts (ET) 8 [XZM11039] (XZM11 =

\section{FeIIICrIII}

SiIVMo11, SiIVW11, PVCoIIW11, PVNiIIW11, PVCuII W11 and PVZnIIW11) and (ET) 8n [PVMnIIM11039] (M = Mo or $W)$ [20]. Of these salts, the latter two are the most interesting as the Keggin clusters form a chainlike heteropolyanion during the course of the electrocrystallization [21].

Considering the facility by which TTF derivatives have been combined with polyoxoanion clusters, especially the dianionic Lindquist polyoxometalates, we sought to prepare a hybrid salt that combined this cluster type 
with the TTF derivative o-3,4-dimethyltetrathiafulvalene (o-Me2TTF) (Fig. 1). This member of the TTF family has been used by the groups of Dunbar and Fourmigue' as a starting material to prepare the redox active chelating diphosphine o-P2 used in various homoleptic transition metal coordination compounds [22-28]. Prior to 2007, the only salt of o-Me2TTF known was (o-Me2TTF) [ReO4]

reported in 1993 where it was oxidized to the ?1 oxidation state [29]. Later, the crystal structure of the neutral donor was published in 1998 [30]. In 2008, Fourmigue' et al. [31] reported the structures and properties of a series of isostructural, tetragonal $2: 1$ salts with the halides $\mathrm{Cl}-\mathrm{Br}$-and

I

which possessed metallic conductivity at room temperature. In 2008 and 2009, Reinheimer et al. [32-34] published separate communications describing the syntheses and structural properties of the salts (o-Me2TTF)[I3], (o-Me2TTF) [BF4] and (o-Me2TTF)2[Re2Cl8] where like the [ReO4]-salt, the o-Me2TTF donor exists as its singly oxidized radical cation. Two years later in 2010, Reinheimer and coworkers reported the 1:1 complex o-Me2TTF-TCNB (TCNB = 1,2, 4,5-tetracyanobenzene), which emphasized the complex's hydrogen bonding network [35].

Herein we present the structure of the hybrid salt (o-Me2TTF) 2[W6019] which combines the unsymmetrical TTF derivative o-Me2TTF with the closed shell Lindquist polyoxometalate [W6019]2-. This structure, together with its single crystal IR and Raman spectroscopy data, are useful for evaluating the o-Me2TTF oxidation state through comparison to theoretical calculations of IR and Raman active modes.

Experimental Section

Preparation of Compounds

For the preparation of the title compound, crystals formed on platinum electrodes of dimensions $1 \mathrm{~mm}$ in diameter and $2 \mathrm{~cm}$ in length in the anodic compartment of a standard electrochemical $\mathrm{H}-\mathrm{cell}$ under low constant current [36]. The organosulfur donor o-Me2TTF and the polyoxoanion (TBA) 2[W6019] were prepared via published techniques $[37,38]$. The solvent $\mathrm{CH} 3 \mathrm{CN}$, used in the electrochemical reactions, was not dried prior to its use.

(o-Me2TTF) $2[$ W6019]

Into both compartments of a standard electrochemical H-cell, (TBA) 2[W6019] (0.107 g, $0.057 \mathrm{mmol})$ was added and dissolved in $10 \mathrm{~mL}$ of $\mathrm{CH} 3 \mathrm{CN}$. The donor o-Me2TTF $(0.0096 \mathrm{~g}, 0.041 \mathrm{mmol})$ was combined with the electrolyte 
CH3

SS

SS

$\mathrm{H}$

$\mathrm{CH} 3$

Fig. 1 o-Me2TTF

123 
solution in the anodic compartment and exposed to a constant current density of 1.0 lA to yield black block-like crystals on the electrode surface which were harvested after a period of 2 weeks, washed with $\mathrm{CH} 3 \mathrm{CN}$, and dried in air.

X-ray Crystallographic Details and Structure Solution

Diffraction quality crystals were grown on the surface of platinum electrodes by slow anodic oxidation of o-Me2TTF in the presence of electrolytic solutions of (TBA)2[W6019] dissolved in CH3CN. A black, block-like crystal of dimensions $0.2090 .1090 .06 \mathrm{~mm} 3$ was secured to a glass fiber using paratone oil and placed into the cold gaseous nitrogen stream of a Bruker APEX II diffractometer using Mo-Ka radiation ( $\mathrm{k}=0.71073 \mathrm{~A}^{\circ}$ ) at110 $\pm 2 \mathrm{~K}$. All data collections were conducted using graphite monochromated radiation and were corrected for Lorentz and polarization effects. Data collection and initial indexing were handled using SMART [39]. Frame integration, Lorentz-polarization corrections, and final cell parameter calculations were carried out using SAINT [40]. Multi-scan absorption corrections were performed using SADABS [41]. The space group P 1 was unambiguously assigned by analysis of symmetry and systematic absences using XPREP and further verified by PLATON [42, 43]. The structure was solved using Patterson methods and difference Fourier techniques. The final structural refinement included anisotropic temperature factors on all non-hydrogen atoms, with the exception of atoms $\mathrm{C} 4$ and Olo which could not be satisfactorily refined anisotropically. Structure solution, refinement, graphics, and creation of publication material were performed using SHELXS, SHELXL and XSEED [44-46]. Hydrogen atoms were inserted at calculated positions and constrained with isotropic thermal parameters. The solid state structure with anisotropic displacement ellipsoids at 50 orobability is shown in Fig. 2. The central $\mathrm{C}=\mathrm{C}$ bond and $\mathrm{C}-\mathrm{S}$ bonds of o-Me2TTF are the most susceptible to its oxidation state and have been used by coppens and coworkers [47] to develop an empirical relationship that can be used to calculate the overall oxidation state of the donor molecules. Information regarding refinement details and bond distances for (o-Me2TTF) 2[W6019] as well calculated average changes for the o-Me2TTF donor in the title salt and other materials are listed in Tables 1-3. CCDC file 890234 contains the supplementary crystallographic data for this paper. These data can be obtained free of charge from The Cambridge Crystallographic Data Centre via www.ccdc.cam.ac.uk/data_request/cif.

Single Crystal Spectroscopic Studies

Raman spectra within the wavenumber range 50-3,500 cm -1 were measured on single crystals of (o-Me2TTF)2[W6019]

using backscattering geometry. The measurements at room temperature were performed on a Labram Horiba Jobin Yvon 800 spectrometer equipped with He-Ne laser (632.8 nm) and 
a liquid-nitrogen cooled CCD detector. To avoid sample overheating and possible decomposition, the power of the exciting laser beam was reduced to $* 0.1 \mathrm{~mW}$. The electrical vector of the exciting laser beam was nearly parallel and perpendicular to the maximum measured intensity for the $\mathrm{C}=\mathrm{C}$ stretching vibrations of $\mathrm{O}-\mathrm{Me} 2 \mathrm{TTF}$, individual molecules of which were aggregated into dimers, approximately perpendicular $(E \backslash a)$ and parallel (E||a) to the crystallographic a-axis.

Fig. 2 (a) View of the unit cell of (o-Me2TTF)2[W6019] illustrating the tendency of the o-Me2TTF radical cations to form face-to-face dimers in the solid state. (b) Detail of the face-to-face overlap between cation radicals. (c) Chain of dimers running along the a axis. The atoms are draw with van der Waals radii 
J Chem Crystallogr (2013) 43:178-186

Table 1 X-ray crystallographic and refinement data for (o-Me2TTF) 2 [W6019]

Compound (o-Me2TTT) 2 [W6019]

CCDC code 890234

Formula C16H16S8W6019

Formula weight 1871.51

Temp. $110(2)$

Space group P1

a, A7.6211(7)

b, A9.5231(9)

$\circ$

C, A12.2148(11)

$\circ$

a, .

$105.5870(10)$

$\mathrm{b}$, .

$106.8340(10)$

C, .

$95.6950(10)$

$\circ 3$

Volume, A802.10(13)

Z1

Density (calculated), mg/m3 3.845

$1, \mathrm{~mm}-122.026$

Scan $x$ scan

h range for data collection, .

$1.83-28.66$

Reflections measured 4092

Independent observed reflns. 3707

Independent reflns. [I [ 2r] 3613

Data/restraints/parameters 3707/0/216

Rint 0.0296

Final R indices [I [ 2r] R1 $=0.0222$,

$\mathrm{wR} 2=0.0550$

$\mathrm{R}$ indices (all data) $\mathrm{R} 1=0.0230$,

$\mathrm{wR} 2=0.0555$

Goodness-of-fit on F2 1.155

2 22] $1 / 2$

$R 1=R|| F O|-| F C|| / R|F \circ| . w R 2=[R \quad[w(F \circ-F C) 2] / R \quad[w(F \circ) 2$.

) ] $1 / 2$

Goodness-of-fit $=[\operatorname{Rw}(|\mathrm{Fo}|-|\mathrm{FC}|) 2 /$ (Nobs -Nparameter

Table 2 Bond distances for (o-Me2TTF)2[W6019]in A 


$$
\begin{aligned}
& W(1)-0(1) \quad 1.694(4) \quad W(3)-0(8) \quad 1.929(3) \\
& W(1)-O(2) \quad 1.917(4) \quad W(3)-0(9) \quad 1.706(4) \\
& W(1)-0(3) \quad 1.928(3) \quad W(3)-0(10) \quad 2.3268(2) \\
& W(1)-O(6) \quad 1.926(3) \quad S(1)-C(1) \quad 1.721(5) \\
& W(1)-O(8) \quad 1.920(3) \quad S(1)-C(2) \quad 1.714(5) \\
& W(1)-O(10) \quad 2.3243(2) \quad S(3)-C(4) \quad 1.706(5) \\
& W(2)-O(2) \quad 1.910(4) \quad S(3)-C(6) \quad 1.736(5) \\
& W(2)-O(4) \quad 1.922(3) \quad S(4)-C(4) 1.718(5) \\
& W(2)-O(5) \quad 1.709(4) \quad S(4)-C(7) \quad 1.739(5) \\
& W(2)-O(6) \quad 1.931(3) \quad C(1)-C(4) 1.391(6) \\
& W(2)-O(7) \quad 1.924(3) \quad C(2)-C(3) \quad 1.332(8) \\
& W(2)-O(10) \quad 2.3221(3) \quad C(5)-C(6) \quad 1.502(7) \\
& W(3)-O(3) \quad 1.910(3) \quad C(6)-C(7) \quad 1.336(7) \\
& W(3)-O(4) \quad 1.931(3) \quad C(7)-C(S) \quad 1.499(7) \\
& W(3)-0(7) \quad 1.911(3)
\end{aligned}
$$

Polarized reflectance spectra were measured from the bestdeveloped crystal face of single crystals $(700-16,000 \mathrm{~cm}-1)$. The spectra were measured for various polarizations of the incident IR beam, which corresponded to maximum and minimum measured intensities of the electronic band at $10,800 \mathrm{~cm}-1$ with electrical vector orientations nearly parallel or perpendicular to the (o-Me2TTF)22? stacking axis. The spectra were recorded using a Bruker Equinox 55 FT-IR spectrometer equipped with a Bruker microscope Hyperion 1000. The reflectance data were normalized to the reflectance of a high quality aluminum mirror.

Results and Discussion

\section{X-Crystallography}

The solid-state structure for (o-Me2TTF) 2[W6019] represents the first charge-transfer salt between the donor o-Me2TTF and the dianionic, diamagnetic Lindquist polyoxoanion [W6019]2-. It has been well established by our group and others that in the absence of any intermolecular contacts such as $\mathrm{p}-\mathrm{p}$ or $\mathrm{S}$ S interactions, neutral chalcofulvalene donors are nonplanar, often exhibiting significant bends of up to 30 . along dithiole or diseleno bridges [22-28]. The solid-state structures of neutral tetrathiafulvalenebased molecules are often controlled by weak van der Waals forces. These interactions define the molecular shape, size, and close packing properties in the solid-state and govern the formation of different patterns of association such as the herringbone conformation in a TTF polymorph and the sandwich herringbone pattern of dimers in the structure of neutral BEDT-TTF [48, 49].

Upon oxidation of the o-Me2TTF donor, structural changes in the molecule occur, including the adoption of a planar conformation followed by a lengthening of the central $\mathrm{C}=\mathrm{C}$ bond and a shortening of the $\mathrm{C}-\mathrm{S}$ bonds in the central TTF core [50-60]. Using the Coppens' formula, the oxidation state for the o-Me2TTF donors was confirmed to be ?1; this was further confirmed upon comparison of 
the central $\mathrm{C}=\mathrm{C}$ and mean $\mathrm{C}-\mathrm{S}$ bond distances from (o-Me2TTF) 2[W6019] to those for other materials known to contain oxidized o-Me2TTF moieties [29-34, 47].

For the title salt, the o-Me2TTF donors exist as strong face-to-face dimers of their corresponding radical cations (Fig. 2a). While this was surmised on the basis of calculation using the Coppens' formula and direct comparison to other o-Me2TTF-containing materials, this aggregation into dimers within the solid state also furnishes a structural indicator. In previous cases of TTF and its derivatives with the dianionic Lindquist polyoxoanions published to date, most salts contain donors in the ?1 oxidation state [8-13]. In those and other cases where radical cations of chalcofulvalene donors 
J Chem Crystallogr (2013) 43:178-186

Table 3 Estimated degree of

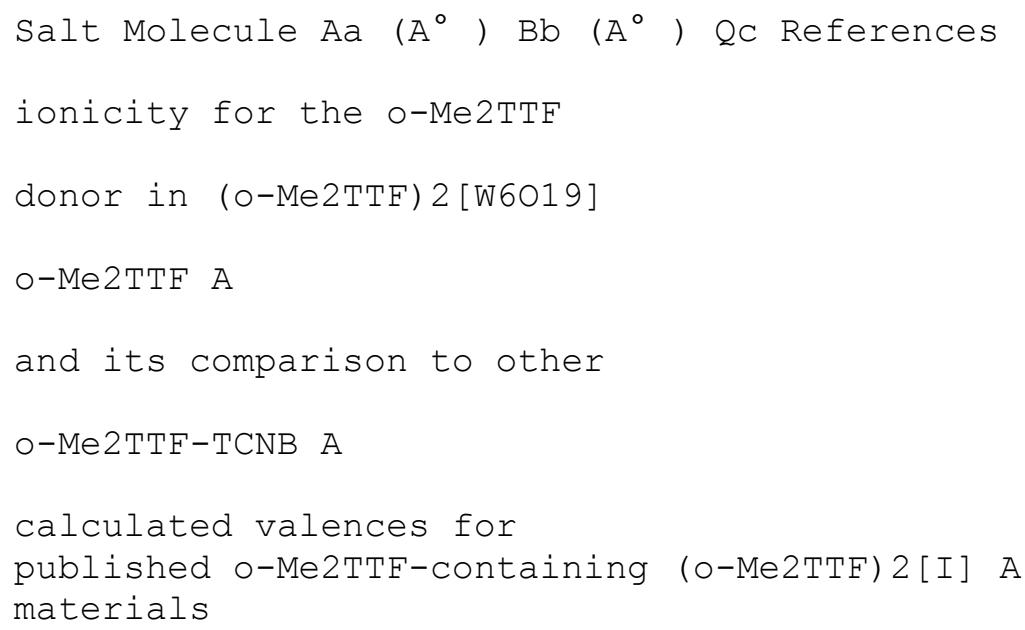


(o-Me2TTF) [ReO4], but is different from the orientation found in (o-Me2TTF) 2[Re2Cl8] where a head-to-head orientation of radicals is observed [32-34].

Commencing with the unit cell, a dimer containing o-Me2TTF radicals was found to be nearly parallel to the ab plane, others can be generated through translations in all directions. For translations along the b-and c-axes, the dimers are effectively separated by the void containing the [W6019]2-polyoxometalate. The polyoxoanion itself is centrally located within the ac plane and related to other symmetry generated polyoxoanions through translations in all three dimensions. Structural features of the [W6019]2polyoxoanion from (o-Me2TTF)2[W6019] are consistent with those observed previously in other TTF-based salts utilizing this anion [8-14].

For o-Me2TTF radical dimers related by translations along the a-axis, their stacking is reminiscent of a stair-step pattern and reveals no close interatomic interactions between neighboring sulfur atoms at distances $13.6 \mathrm{~A}^{\circ}$ (Fig. 2C). Despite appearing that there may be long range interactions between sulfur atoms along the a-axis, there is no satisfactory long range stacking between the oxidized

$1.340(4) \quad 1.762(3) \quad 0 \quad[30]$

$1.342(7) \quad 1.755(2) \quad 0 \quad[33]$

$1.365(5) \quad 1.738(4) \quad ? 0.48[31]$

$1.365(5) \quad 1.738(4) \quad ? 0.48$

$1.39(1) \quad 1.716(5) \quad ? 1.06 \quad[29]$

$1.401(5) \quad 1.722(4) \quad ? 1.14 \quad[32]$

$1.386(4) \quad 1.721(2) \quad ? 0.95 \quad[33]$

$1.401(3) \quad 1.715(3) \quad ? 1.22 \quad[34]$

$1.373(2) \quad 1.717(4) \quad ? 0.82$

$1.391(5) 1.716(4)$ ? 1.07 This study

$1.391(5) 1.716(4) \quad ? 1.07$

o-Me2TTF moieties which could lead to either activated or non-activated conductivity as short intradimer $\left(\backslash 3.6 \mathrm{~A}^{\circ}\right.$ )

and longer interdimer $\left(\left[3.6 \mathrm{~A}^{\circ}\right)\right.$ interactions exist in an alternating pattern involving the o-Me2TTF radicals and successive dimers respectively along a.

Among the solid structure for (o-Me2TTF) 2[W6019], hydrogen bonding interactions, which can be suggested if interatomic distances between oxygen and hydrogen atoms are $\backslash 2.70 \mathrm{~A}^{\circ}$ (the sum of their corresponding van der Waals radii), were found between hydrogen atoms bound to sp 2-hybridized carbon atoms from o-Me2TTF and the bridging oxygen atoms of the [W6019]2-polyoxoanion clusters. A 1999 report by Batail and coworkers [62] demonstrated, by the use of by electrostatic potential maps, that bridging oxygen atoms in these clusters are more basic and thus better hydrogen bond acceptors than those in terminal positions. Within our structure (Fig. 3), short Csp2-H O interactions of 2.296 and $2.512 \mathrm{~A}^{\circ}$ exist between H8-09 and H7-04 respectively within the (111) plane. In 
both cases, a bridging oxygen atom from the tungsten cluster acts as a hydrogen bonding acceptor. While other interactions between hydrogen and oxygen atoms at distances $\backslash 2.70 \mathrm{~A}^{\circ}$ were found, their close approximation (within $* 0.03-0.07 \mathrm{~A}^{\circ}$ ) to the threshold value of $2.70 \mathrm{~A}^{\circ}$ makes their identification as actual hydrogen bonding interactions problematic. The fact that the observed Csp2$\mathrm{H} \quad \mathrm{O}$ interactions are well below the threshold value of

2.70 Aand involve bridging oxygen atoms from the [W6019]2-cluster, provides structural support that those particular oxygen atoms from the cluster, with their elevated basicity, are better hydrogen bond acceptors than their terminal counterparts.

Single crystal spectroscopic Properties

In previous spectroscopic measurements on o-Me $2 \mathrm{TTF}$ containing materials, particularly the neutral donor and the

$2: 1$ salts $(\mathrm{O}-\mathrm{Me} 2 \mathrm{TTF}) 2[\mathrm{X}] \quad(\mathrm{X}=\mathrm{Cl}-, \mathrm{Br}-\mathrm{and} \mathrm{I}-)$ where 123 
Fig. 3 Detail of the hydrogen bond pattern (see text). Anisotropic displacement ellipsoids have been set to 50 o probability

o-Me2TTF bears a ?1/2 charge, IR and Raman spectra were successfully measured [63]. During the course of those studies, the normal vibrational modes of the neutral and the radical cation, as well as their theoretical IR and Raman spectra, were calculated by quantum chemical methods. Utilizing these theoretical calculations, experimentally observed vibrational features of o-Me2TTF were assigned [63]. For (o-Me2TTF)2[W6019], the solid state structure reveals that each donor molecule bears a ?1 charge and aggregates with other o-Me2TTF radical cations to form isolated dimers. Upon consideration of the structural features of the (o-Me2TTF)2[W6019] salt, the isolated dimer model can be used to explain the features of the spectra. In this model, one can distinguish two dimeric modes: the in-phase vibration of monomers, which is Raman active, and the out-of-phase mode, which is IR active due to coupling with the electronic transition.

The Raman spectra of the title salt are displayed in Fig. 4 for two polarizations of the incident laser beam which were nearly parallel and perpendicular to the stacking axis of the o-Me2TTF radical cations in the isolated dimers, that being the crystallographic a-axis. For perpendicular polarization, the strongest bands for $\mathrm{O}-\mathrm{Me} 2 \mathrm{TTF}$ ? are attributed to the $\mathrm{C}=\mathrm{C}$ stretching modes $(\mathrm{m} 9=1,556 \mathrm{~cm}-1, \mathrm{~m} 10=1,483$ $\mathrm{cm}-1, \mathrm{~m} 11=1,417 \mathrm{~cm}-1)$ and the ring breathing mode $(\mathrm{m} 38=518 \mathrm{~cm}-1)[63]$. These experimental data compare closely with those stretches determined theoretically: $\mathrm{m} 9=1,603 \mathrm{~cm}-1, \mathrm{~m} 10=1,546 \mathrm{~cm}-1, \mathrm{~m} 11=1,436 \mathrm{~cm}-1$, $\mathrm{m} 38=482 \mathrm{~cm}-1$ [63]. In the spectrum we also find some other bands related to the o-Me2TTF radical cations: $\mathrm{m} 20=1,101 \mathrm{~cm}-1 \quad(\mathrm{C}-\mathrm{H}$ bend $), \mathrm{m} 21=1,036 \mathrm{~cm}-1 \quad(\mathrm{C}-\mathrm{C}$ stretch), $\mathrm{m} 25=975 \mathrm{~cm}-1(\mathrm{C}-\mathrm{S}$ stretch $), \mathrm{m} 26=937 \mathrm{~cm}-1$ $(\mathrm{C}-\mathrm{S}$ stretch, $\mathrm{C}-\mathrm{C}$ stretch), $\mathrm{m} 31=754 \mathrm{~cm}-1$ (rock CH3), $\mathrm{m} 32=720 \mathrm{~cm}-1(\mathrm{C}-\mathrm{S}$ stretch), $\mathrm{m} 34=627 \mathrm{~cm}-1$ (in-plane deformation), $\mathrm{m} 40=473 \mathrm{~cm}-1$ (ring breath), $\mathrm{m} 45=274$ $\mathrm{cm}-1$ (in-plane deformation), $\mathrm{m} 47=234 \mathrm{~cm}-1$ (out-of-plane deformation) [63]. The anion W60192-has 11 Raman active modes [64]. In the spectrum of (o-Me2TTF)2[W6019]we observe 7 bands assigned to W60192-anions: $\mathrm{ml}(\mathrm{alg})=995$ $\mathrm{cm}-1, \mathrm{~m} 6(\mathrm{eg})=968 \mathrm{~cm}-1, \mathrm{~m} 7(\mathrm{eg})=830 \mathrm{~cm}-1, \mathrm{~m} 2(\mathrm{a} 1 \mathrm{~g})=$ $555 \mathrm{~cm}-1, \mathrm{~m} 8(\mathrm{eg})=501 \mathrm{~cm}-1, \mathrm{~m} 1(\mathrm{alg})=228 \mathrm{~cm}-1$ and

500100015002000

0

500

1000

1500

0 
4000

5000

6000

7000

[o-DMTTF] 2W6019

E aIntensityT

141714831556

E II aIntensity

[o-DMTTF] 2W6019

141714831556

518518

Raman Shift [cm-1]

Fig. 4 Raman spectrum of (o-Me2TTF)2[W6019] obtained with a red excitation (632.8 $\mathrm{nm})$ for two perpendicular polarizations of the laser beam

$\mathrm{m} 9(\mathrm{eg})=181 \mathrm{~cm}-1$. These wavenumbers agree quite well

with those reported in Reference 64.

It is well-known that the $\mathrm{C}=\mathrm{C}$ modes of TTF derivatives

are very sensitive to the degree of oxidation and as such are

often used for the determination of charge density distribution

[47]. Based on the behavior of these modes for

charge transfer salts of TMTTF, ET and bis(ethylenedioxo)

tetrathiafulvalene (BEDO-TTF), their $\mathrm{C}=\mathrm{C}$ bond frequencies

depend linearly (or nearly linearly) on charge

density. When the average oxidation state grows, the

wavenumber for the $\mathrm{C}=\mathrm{C}$ modes decreases considerably by

*60-110 cm -1 per ?1 charge. For the title salt, a similar

nearly linear charge dependency was observed for the

analogous $\mathrm{C}=\mathrm{C}$ modes of the $\mathrm{O}-\mathrm{Me} 2 \mathrm{TTF}$ donor and is

represented within Fig. 5 where we outline the spectral

response for selected Raman active bands for o-Me2TTFO,

o-Me2TTF?0.5 and the present data for o-Me2TTF ?

Concurrently, when the donor's oxidation state increases,

the ring breathing mode, m38, shifts towards higher wavenumbers

(*23 cm -1 per ?1 charge). Such spectroscopic

behavior is equivalent to that seen for other TTF derivatives

[65-67].

The polarized reflectance spectrum for (o-Me2TTF) 2

[W6019] is shown in Fig. 6 for polarizations parallel (E||a)

123 
J Chem Crystallogr (2013) 43:178-186

1650

towards lower wavenumbers because of the e-mv coupling

effect. Similar shift patterns were also observed for charge

transfer salts containing other TTF derivatives, thus pro

\section{0}

viding evidence suggesting strong electronic coupling.

In the IR spectrum we also find two bands related to $\mathrm{C}-\mathrm{S}$

$0.0 \quad 0.51 .0$

.11

.10

.9

stretching modes: the m25 mode at $988 \mathrm{~cm}-1$ (E/|a) activated by e-mv coupling and the IR active m30 mode at $795 \mathrm{~cm}-1$

\section{0}

Wavenumber $(\mathrm{cm}-1)$

observed for both polarizations $(779 \mathrm{~cm}-1$ for neutral

1500

o-Me2TTF [63]). Additionally, in the reflectance spectrum we observe 3 bands assigned to the [W6019]2-anion:

m14 $(t 1 u)=972$ and $966 \mathrm{~cm}-1$ (doublet), m15(t1u) $=830 \mathrm{~cm}-1$

1450

and $\mathrm{ml} 6(\mathrm{tlu})=576 \mathrm{~cm}-1$ [64]. The dimer model originally developed for K-TCNQ and later applied to (ET)2[Mo6019],

1400

provided reliable estimates of electron-molecular coupling constants for TCNQ - and BEDT-TTF ?, respectively [68,

Charge $(+e)$

69]. Analogously, the IR spectra for (o-Me2TTF)2[W6019]

Fig. 5 Frequencies of the $\mathrm{C}=\mathrm{C}$ stretching modes of o-Me2TTF

can be used for determination of electron-molecular coupling molecule versus ionization degree

constants for the o-Me2TTF ?

0.0

0.1 


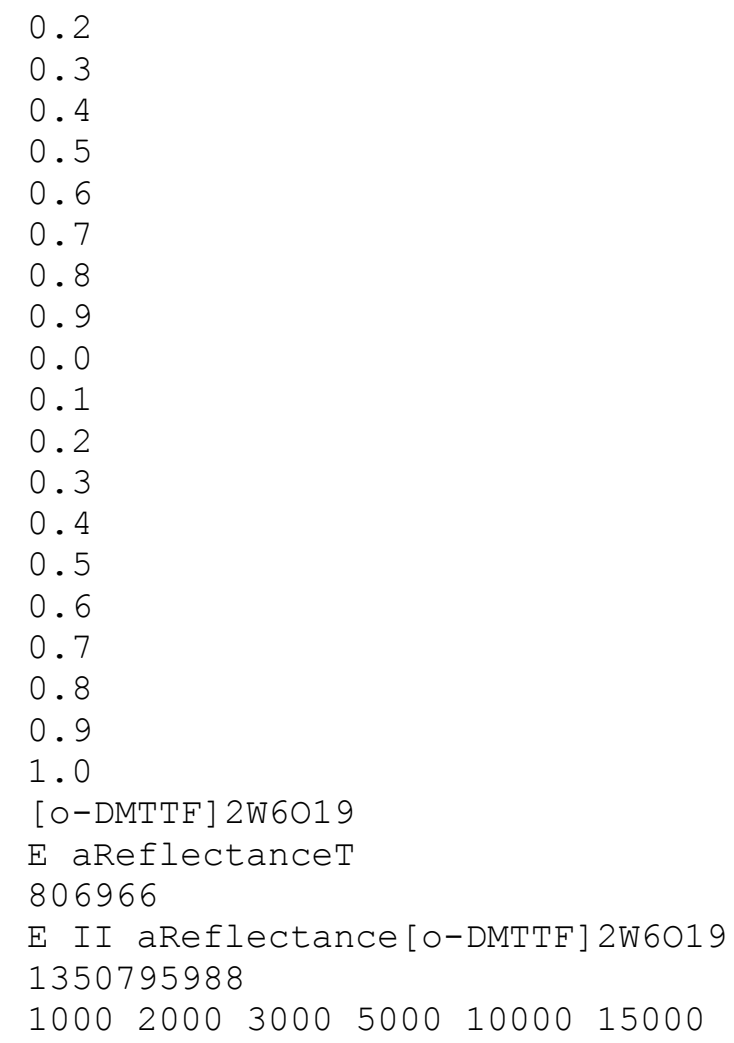

Conclusions

Herein we describe the $\mathrm{x}$-ray crystallographic structure and spectroscopic properties of the hybrid charge transfer salt (o-Me2TTF)2[W6019] which contains radical cations of the unsymmetrical TTF derivative o-Me2TTF and the closed shell Lindquist polyoxometalate [W6019]2-. Close inspection of the structure revealed isolated dimers of o-Me2TTF radical cations encompassing strong face-toface overlap and intradimer $S \mathrm{~S}$ interactions between neighboring sulfur atoms at distances $\backslash 3.6 \mathrm{~A}^{\circ}$. These

Wavenumber $[\mathrm{cm}-1]$

Fig. 6 Reflectance spectrum of (o-Me2TTF)2[W6019] salt for two perpendicular polarizations, corresponding to maximum (E||a) and minimum (E\a) intensity of the electronic transition at 10,800 $\mathrm{cm}-1$

and perpendicular (E\a) to the dimer axis. For polarization nearly parallel to the dimer axis, we observe an electronic band at $\star 10,800 \mathrm{~cm}-1$, corresponding to an intradimer charge transfer transition. This band is a characteristic feature of the salts containing dimers of TTF-type radical cations; for example, in (ET)2[Mo6019] and (DMtTTF)

[Br], this band was located at 7,000 and $8,300 \mathrm{~cm}-1$ respectively [68]. It is remarkable that in (o-Me2TTF) 2 [W6019], this electronic transition is located at higher frequency, i.e. the interaction between the o-Me2TTF radical cations within the dimer is smaller. The relatively strong vibrational feature at $1,350 \mathrm{~cm}-1$ (E||a) is related to the effect of electron-molecular vibration (e-mv) coupling of the mil mode ( $C=C$ central bond stretching) with the 
charge-transfer transition. In comparison with the analogous Raman band, this IR feature is shifted by $67 \mathrm{~cm}-1$

structural features are strongly indicative of regions of charge localization which ultimately result in insulating properties. Hydrogen bonds between bridging oxygen

atoms of the polyoxometalate cluster and the o-Me2TTF radicals were also observed at distances well below the threshold value of $2.70 \mathrm{~A}^{\circ}$. As these interactions involve the bridging oxygen atom of the cluster, it supports the computationallydetermined hypothesis that bridging oxygen

atoms of polyoxometalate clusters, with their heightened basicity, are better hydrogen bond acceptors than their terminal analogues. Single crystal spectroscopic studies were also completed on the IR and Raman active modes of the oxidized o-Me2TTF donor. Identification and analysis of these modes correlate with theoretical spectra for o-Me2TTF ? determined using quantum chemical methods. The frequency change for the $\mathrm{C}=\mathrm{C}$ mode in o-Me2TTF with respect to oxidation state follows a linear (or nearly linear) trend as seen for other TTF derivatives. Finally, a strong intradimer charge transfer transition was observed at $\star 10,800 \mathrm{~cm}-1$, which is indicative of the dimerization of TTF-type radical cations in the solid state. The title salt adds another 2:1 phase to the library of salts containing 
TTF derivatives and the [W6019]2-anion and provides IR and Raman stretches for the o-Me2TTF donor in its radical cation form, spectral information important for continuing studies on complexes containing this organic donor.

Acknowledgments This work was supported by the Polish-French Polonium 2009-2010 Program No. 20083YF, the CNRS-PAN program, and by the French Agence Nationale de la Recherche (Contract No. BLAN08-3 317277) for financial support. MF also thanks the ANR for additional financial support (Contract No. 08-BLAN-0140 3/4-Filled). EWR thanks the French Government for financial support in the form of a Chateaubriand Fellowship (Dossier \#634148J). We also thank Thierry Roisnel (CDIFX Rennes) for the X-ray data collection.

\section{References}

1. Coronado E, Day P (2004) Chem Rev 104:5419

2. Ferraris J, Cowan DO, Walatka VJ, Perlstein JH (1973) J Am Chem Soc 95:948

3. Bechgaard K, Jacobsen CS, Mortensen K, Pedersen HJ, Thorup N (1980) Solid State Commun 33:1119

4. Williams JM, Ferraro JR, Thorn RJ, Carlson KD, Geiser U, Wang HH, Kini AM, Whangbo M-H (1992) Organic superconductors. Prentice Hall, Englewood Cliffs

5. Kurmoo M, Graham AW, Day P, Coles SJ, Hursthouse MB, Caulfield JL, Singleton J, Pratt FL, Hayes W, Ducasse L, Guinneau P (1995) J Am Chem Soc 117:12209

6. Coronado E, Gala'n-Mascaro's JR, Go'mez-Garcia CJ, Laukhin V (2000) Nature 408:447

7. Coronado E, Go'mez-Garci'a CJ (1998) Chem Rev 98:273

8. Triki S, Ouahab L, Padiou J, Grandjean D (1989) J Chem Soc Chem Commun 1068

9. Bellitto C, Attanasio D, Bonamico M, Fares V, Imperatori $\mathrm{P}$, Patrizio S (1990) Mater Res Soc Symp Proc 173:143

10. Triki S, Ouahab L, Grandjean D (1991) Acta Crystallogr C47:645

11. Coronado

E, Gala'n-Mascaros JR, Gime'nez-Saiz C, Go'mezGarci

'a CJ, Rovira C, Tarre's J, Triki S, Veciana J (1998) J Mater Chem $8: 313$

12. Triki S, Ouahab L, Grandjean D, Amiel J, Garrigou-Lagrange C, Delhaes P, Fabre JM (1991) Synth Met 42:2589

13. Triki S, Ouahab L (1993) Acta Crystallogr C49:132-135

14. Reinheimer

EW, Fourmigue' M, Dunbar KR (2009) J Chem

Crystallogr 39:723

15. Triki S, Ouahab L, Halet JF, Peña O, Padiou J, Grandjean D, Garrigou-Lagrange C, Delhaes P (1992) J Chem Soc Dalton Trans 1217

16. Triki S, Ouahab L, Grandjean D (1991) Acta Crystallogr C49:132 17. Triki S, Ouahab L, Grandjean D, Canet R, Garrigou-Lagrange C, Delhaes P (1993) Synth Met 55-57:2028

18. Coronado

E, Ga'lan-Mascaro's JR, Gime'nez-Saiz C, Go'mezGarci

'a CJ, Marti'nez-Ferrero E, Almeida M, Lopes EB (2004)

Adv Mater 16:324

19. Coronado 
E, Ga'lan-Mascaro's JR, Gime'nez-Saiz C, Go'mezGarci

'a CJ, Laukhin VN (1996) Adv Mater 8:801

20. Coronado

E, Ga'lan-Mascaro's JR, Gime'nez-Saiz C, Go'mezGarci

'a CJ, Triki S (1998) J Am Chem Soc 120:4671

21. Ga'lan-Mascaro's JR, Gime'nez-Saiz C, Triki S, Go'mez-Garci'a CJ,

Coronado E, Ouahab L (1995) Angew Chem Int Ed Engl 34:1460

22. Fourmigue' M, Uzelmeier CE, Boubekeur K, Bartley SL, Dunbar

KR (1997) J Organomet Chem 529:343

23. Smucker BW, Dunbar KR (2000) Dalton Trans 1309

24. Uzelmeier

CE, Smucker BW, Reinheimer EW, Shatruk M,

O'Neal A, Fourmigue' M, Dunbar KR (2006) Dalton Trans 5259

25. Avarvari N, Fourmigue' M (2004) Chem Commun 1300

26. Avarvari N, Martin D, Fourmigue' M (2002) J Organomet Chem

$643-644: 292$

27. Gouverd C, Biaso F, Cataldo L, Berclaz T, Geoffroy M, Levillain

E, Avarvari N, Fourmigue' M, Sauvage FX, Wartelle C (2005)

Phys Chem Chem Phys 7:85

28. Kobayashi

A, Fujiwara E, Kobayashi H (2004) Chem Rev

$104: 5243$

29. Mhanni A, Ouahab L, Grandjean D, Amoroux J, Fabre JM (1993)

Acta Crystallogr C49:1187

30. Uzelmeier CE, Fourmigue' M, Dunbar KR (1998) Acta Crystallogr

C54:1047

31. Fourmigue' M, Reinheimer EW, Dunbar KR, Auban-Senzier P,

Pasquier C, Coulon C (2008) Dalton Trans 4652

32. Reinheimer

EW, Fourmigue' M, Dunbar KR (2009) J Chem

Crystallogr 39:735

33. Reinheimer EW, Zhao H, Dunbar KR (2008) Synth Met 158:447

34. Reinheimer EW, Gala'n-Mascaro's JR, Go'mez-Garci'a CJ, Zhao H, Fourmigue' M, Dunbar KR (2008) J Mol Struc 890:81

35. Reinheimer EW, Zhao H, Dunbar KR (2010) J Chem Crystallogr $40: 514$

36. Batail P, Boubekeur K, Fourmigue' M, Gabriel JCP (1998) Chem

Mater 10:3005

37. Che M, Fournier M, Launay JP (1979) J Chem Phys 71:1954

38. Gerson F, Lamprecht A, Fourmigue' M (1996) J Chem Soc Perkin

Trans 2:1409

39. SMART (1998) Software for the CCD detector system, version

5.050 (NT). Bruker Analytical X-ray Systems, Madison

40. SAINT (1998) Software for the CCD detector system, version

5.01 (NT). Bruker Analytical X-ray Systems, Madison

41. Blessing RH (1995) SADABS, program for absorption corrections using Siemens CCD based on the method of Robert

Blessing. Acta Crystallogr A 51:33

42. Sheldrick GM (1996) XPREP, program for space group determination.

University of Go"ttingen, Go"ttingen

43. Speck AL (2001) PLATON, a multipurpose crystallographic tool.

Utrecht University, Utrecht

44. Sheldrick GM (1997) SHELXS-97, program for crystal structure

determination. University of Go"ttingen, Go"ttingen

45. Sheldrick

GM (1997) SHELXL-97, program for the crystal

structure refinement. University of Go"ttingen, Go"ttingen

46. Barbour LJ (2001) J Supramol Chem 1:189 
47. Umland TC, Allie S, Kuhlmann T, Coppens P (1987) J Phys Chem 92:6456

48. Ellern A, Bernstein J, Becker JY, Zamir S, Shalal L, Cohen S (1994) Chem Mater 6:1378

49. Cooper WF, Edmonds JW, Wudl F, Coppens P (1974) Cryst

Struct Commun 3:23

50. Alberola A, Coronado E, Gala'n-Mascaro's JR, Gime'nez-Saiz C, Go'mez-Garci'a CJ (2003) J Am Chem Soc 125:10774

51. Coronado

E, Gala'n-Mascaro's JR, Go'mez-Garci'a CJ, MurciaMarti

'nez A, Canadell E (2004) Inorg Chem 43:8072

52. Coronado E, Gala'n-Mascaro's JR, Go'mez-Garci'a CJ, Marti'nezFerrero E, van Smaalen S (2004) Inorg Chem 43:4808

53. Clemente-Leo'n M, Coronado E, Gala'n-Mascaro's JR, Gime'nezSaiz C, Go'mez-Garci'a CJ, Ribera E, Vidal-Gancedo J, Rovira C, Canadell E, Laukhin V (2001) Inorg Chem 40:3526

54. Clemente-Leo'n M, Coronado E, Gala'n-Mascaro's JR, Gime'nezSaiz C, Go'mez-Garci'a CJ, Rovira C, Laukhin VN (1999) Synth Met 103:2339

55. Clemente-Leo'n M, Coronado E, Gala'n-Mascaro's JR, Gime'nezSaiz C, Go'mez-Garci'a J, Fabre JM (1999) Synth Met 103:2279

56. Kobayashi H, Tomita H, Naito T, Kobayashi A, Sakai Watanabe T, Cassoux P (1996) J Am Chem Soc 118:368

57. Bousseau M, Valade L, Legros JP, Cassoux P, Garbauskas M, Interrante LV (1986) J Am Chem Soc 108:1908

123 
J Chem Crystallogr (2013) 43:178-186

58. Perruchas S, Boubekeur K, Auban-Senzier P (2004) J Mater Chem 14:3509

59. Kazheva ON, Alexandrov GG, Dyachenko OA, Zinenko TN, Kravchenko AV, Starodub VA, Khotkevich AV (2006) Synth Met $156: 251$

60. Chi X, Scott B, Lawes G, Ramirez AP (2004) J Chem Crystallogr $34: 249$

61. Fourmigue' M, Batail P (2004) Chem Rev 104:5379

62. Dolbecq A, Guirauden A, Fourmigue' M, Boubekeur K, Batail P, Rohmer MM, Be'nard M, Salle' M, Blanchard P (1999) J Chem

Soc Dalton Trans 1241

Raman spectr 42:1518

63. Jankowski D, S wietlik R, Reinheimer EW, Fourmigue' M (2011) J

64. Bridgeman AJ, Cavigliasso G (2002) Chem Phys 279:143

65. Meneghetti M, Bozio R, Zanon I, Pecile C, Ricotta C, Zanetti M (1984) J Chem Phys 80:6210

66. Yamamoto T, Uruichi M, Yamamoto K, Yakushi K, Kawamoto

A, Taniguchi H (2005) J Phys Chem B 109:15226

67. Drozdowa O, Yamochi H, Yakushi K, Uruichi M, Horiuichi S, Saito G (2000) J Am Chem Soc 122:4436

68. Visentini G, Masino M, Bellitto C, Girlando A (1998) Phys Rev B $58: 9460$

69. Rice MJ, Lipari NO, Stra“ssler S (1977) Phys Rev Lett 39:1359 123 
